\title{
Opportunities, Quality Factors, and Required Changes during the Pandemic Based on Higher Education Leaders' Perspective
}

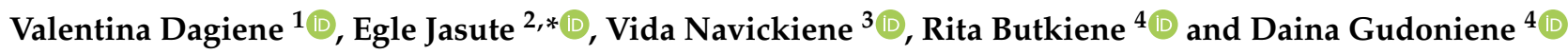 \\ 1 Institute of Data Science and Digital Technologies, Vilnius University, Akademijos str. 4, \\ LT-08412 Vilnius, Lithuania; valentina.dagiene@mif.vu.lt \\ 2 Institute of Educational Sciences, Vilnius University, Universiteto str. 9, LT-01513 Vilnius, Lithuania \\ 3 Faculty of Creative Industries, Vilnius Gediminas Technical University, Sauletekio al. 11, \\ LT-10223 Vilnius, Lithuania; vida.navickiene@vilniustech.lt \\ 4 Faculty of Informatics, Kaunas University of Technology, Studentu str. 50, LT-44249 Kaunas, Lithuania; \\ rita.butkiene@ktu.lt (R.B.); daina.gudoniene@ktu.lt (D.G.) \\ * Correspondence: egle.jasute@fsf.vu.lt
}

Citation: Dagiene, V.; Jasute, E.; Navickiene, V.; Butkiene, R.;

Gudoniene, D. Opportunities, Quality Factors, and Required Changes during the Pandemic Based on Higher Education Leaders' Perspective. Sustainability 2022, 14 , 1933. https://doi.org/10.3390/ su14031933

Academic Editors: Julio Ruiz-Palmero and Melchor Gómez-García

Received: 23 December 2021

Accepted: 3 February 2022

Published: 8 February 2022

Publisher's Note: MDPI stays neutral with regard to jurisdictional claims in published maps and institutional affiliations.

Copyright: (c) 2022 by the authors. Licensee MDPI, Basel, Switzerland. This article is an open access article distributed under the terms and conditions of the Creative Commons Attribution (CC BY) license (https:// creativecommons.org/licenses/by/ $4.0 /)$.

\begin{abstract}
The pandemic period in education brought many challenges to all organizations. The activities of the higher educational institutions are being affected and the situation can last for a longer time. Under these circumstances, it is important to shift to online learning and improve educational processes through all organizational levels. The organizations had to assure appropriate distance or remote learning process by identifying their opportunities, meeting challenges, and identifying the sustainable quality factors for remote or distance learning. This study aimed to map and test the factors that influence online learning success in the pandemic situation in higher education in one of the European Union countries, Lithuania. Factors analyzed and presented in the paper are the quality of institutions and services, infrastructure and system quality, quality of courses and information, and online learning environment. Data were collected through surveys by distributing questionnaires and interviews. Authors are providing the main criteria for successful education based on administrative positions and design makers of the educational organizations. The article summarizes the interviews of 15 respondents from the three Lithuanian higher education institutions and how their informants met changes, opportunities, and identified quality factors addressed to the successful learning and teaching process during a pandemic period.
\end{abstract}

Keywords: higher education; sustainability during the pandemic; opportunities; quality factors; distance teaching

\section{Introduction and Background}

Distance teaching is not considered to be a novelty, but educational institutions still face many challenges regarding their organization and implementation. Academics play a significant role as facilitators of online learning. Due to a sudden pandemic and shift to online learning, many academics did not have adequate time to adjust to the new teaching platforms [1,2]. Currently, education has globally transformed and moved to online due to the pandemic; however, it is unknown whether this transformation produces more positive teaching and learning outcomes than negative issues. There are many issues raised. How does this proposed variety of different tools and environments affect a student who has to connect to as many different systems as there are lectures on that day? Can the safety of students online be guaranteed if they are registering in systems and resources that are not state-controlled and that may not guarantee the security of their data? What are the opportunities and quality factors of online education? What changes are required in educational institutions?

Higher education has transformed and moved online; however, it is not clear whether this transformation produces positive studies outcomes. Many researchers across the 
world have conducted hundreds of studies. Various kinds of tools to facilitate learning environments when using online systems have been investigated, for example, Tencent Meeting System [3] or Topic Analysis Instant Feedback System [4].

In order to better understand the organization's educational processes during the pandemic period, a systematic literature review was conducted on Web of Science (WOS) Clarivate Analytics and Scopus databases for relevant studies published during the last two years. The search terms used were 'COVID-19', 'coronavirus', 'pandemic', in combination with 'online learning', 'distance learning', 'e-learning', 'e-teaching', and 'higher education'. A total of 586 papers were found in the WOS core collection alone and an additional 201 papers in Scopus. An inclusion and exclusion criteria were developed to select the most relevant articles which focus on opportunities, quality factors, and required changes in online studies.

The main goal during the literature analyses was to investigate the organization's sustainable education processes, to elicit relevant evidence on e-learning and e-teaching outcomes, opportunities, quality factors, and required changes in higher education during the pandemic period. Special attention was paid to the systematic review papers aimed at online education issues during the pandemic [5-8].

An unexpected implementation of online teaching and learning has brought numerous challenges to higher education processes. The major challenges such as academics' and students' difficulties to adjust, lack of teaching and learning resources, and mental health-related issues, are associated with the sudden transfer to learning which was not prepared for. Mental health-related issues include stress, anxiety, and depression that occur due to lockdown and especially due to the uncertainty about the future situation [9-11]. Evidence shows that some academics lack knowledge of information technology and online teaching [12-14]. Conducting assessments online appears to be the most challenging issue and requires very good preparation $[5,15,16]$. Lack of teaching and learning resources adapted to pure online education was one of the major concerns in many papers [17-19]. A significantly increased demand for the organization of distance learning requires large amounts of computer, communication and information resources, sufficient bandwidth of communication channels, and raises cybersecurity issues while utilizing hardware and software from various, often uncertified and unreliable manufacturers. Challenges with connectivity were mentioned as the leading factor undermining online studies during the pandemic lockdown [18,20-23].

According to studies, face-to-face approaches are preferred by most academics and students. The results of the study show an increase in students' academic performance in emergency remote teaching and support the idea that organizational factors may contribute to the successful implementation of emergency remote teaching [24]. Student engagement was likely negatively impacted by the emergency transition to remote teaching. Lecturers engaged students less after the transition. By contrast, course activities that did not heavily rely on a physical classroom, such as students blogging and working on an independent research paper, were more effective in retaining student engagement after the transition [25].

Adjusting studies to online learning posed various challenges to educational institutions. The main question that is of interest to many educators and education policymakers is whether online learning is better and more effective than class-based learning [26-28].

Numerous research works have been published on case studies in online education in various countries such as China, Hong Kong, South Korea, India, Indonesia, and Ukraine [2,23,29-32]. However, only a few studies address the opportunities and challenges presented by the pandemic situation [7,33-36]. While many studies have been published on higher response to COVID-19 [17,29,37-40], only a few studies address the depth of e-learning and e-teaching outcomes, associated challenges and opportunities during the pandemic [41,42].

Despite the pandemic situation that has created many problems for higher education institutions, some positive effects and new opportunities have been recognized. The rapid shift in instructional platform presents an opportunity to learn from unresolved challenges 
that persisted throughout the semester. Four major aspects-personal factors, contextual factors of the structure and culture, teacher thinking, and teachers' practice-revealed that the professors in this study adapted quickly using institutionally offered platforms, modified their courses as little as possible, struggled with assessment, and held diverging beliefs about teaching and students. The opportunities have implications for ongoing efforts to reform instructional practices at the institutional and departmental levels [43]. Several innovative approaches and tools for learning online were developed [44]. Many educators have developed innovative learning experiences making use of creativity, virtual reality, online discussion boards, virtual tours, Jam Boards, videos, and breakout rooms [45]. Study resources were revised, restructured, and adapted for student's self-directed learning. This unexpected and rapid transition to online learning has led to a multiplication of teachers' strategies for distance learning in lectures, tutorials, project groups, lab works, and assessments. Teachers have shown resilience during this crisis that required significant personal commitment. They admit that they have learned more about distance education in two months than they did in the last 10 years [46]. Our emergence from the pandemic provides an opportunity for deep reflection and intentional action about what is taught and why, as well as how student learning is facilitated. It is suggested that the need to design and implement new ways of teaching and learning is based on fundamentally reimagined learning outcomes for our courses that equip students for life after the rupture they have experienced [45]. Academics and students were fostered to improve their digital competencies. The lockdown due to SARS-CoV-2 (COVID-19) pandemic forced both educators and students to shift and rely on digital technologies in order to ensure the successful completion of modules based on the official curriculum [47]. These changes and opportunities create a space for innovative thinking and innovative solutions $[33,48-50]$. Thus, the opportunities discussed and discovered can be seen as quality factors for distance learning and provide the basis for the required changes in the study process.

\section{Research Design and Methodology}

To conduct a qualitative study, a phenomenographic research methodology was employed. The devised strategy is based on the view that people understand and perceive phenomena differently but their perceptions are interrelated. The goal of the strategy is to present a variety of aspects describing the experience of a particular phenomenon [51]. Phenomenographic research not only identifies the categories that describe the phenomenon under consideration but also reveals hidden, tacit profound meaning and presents their interrelationships. The distinguished categories form a hierarchical horizontal order.

The aim of the paper is to analyze the organizing education processes during the pandemic period emphasizing opportunities, sustainable quality factors, and required changes. The conceptual framework of this research is presented in Figure 1. The research method is based on a qualitative content survey conducted during June 2020. A semi-structured interview method was used. Critical selection of informants was used to demonstrate a deep understanding of the phenomenon. The main criteria considered were as follows: (a) informant is from one of the largest Lithuanian universities (size); (b) from different types of university: classical university and broad profile universities from different cities (type); (c) leaders are available in the university, whose functions are related to the management of studies (taking highest positions in the university, then leaders of lower rank (deans of faculties of humanities, social, technological, engineering sciences, heads of other divisions, who were chosen to make sure that the position of authorities is the same in terms of the range of qualitative changes influenced by the pandemic); (d) informants-experts in their field with at least 7 years of managerial experience related to the analyzed phenomenon (experts, working experience). The triangulation of experts aimed to ensure the validity of the research. Therefore, the three largest universities of Lithuania were selected for the qualitative research and two of them, technology-oriented universities, are located in different cities and the third one is a classical university. The aim of using such selection criteria was to obtain the widest possible coverage of the information. Fifteen informants 
participated in the research. It was the top management of the universities: vice-rectors of studies (3), study directors (3), deans of different faculties (4), and vice-deans (5). The verbal consent to take part in the interview was received from all the informants.

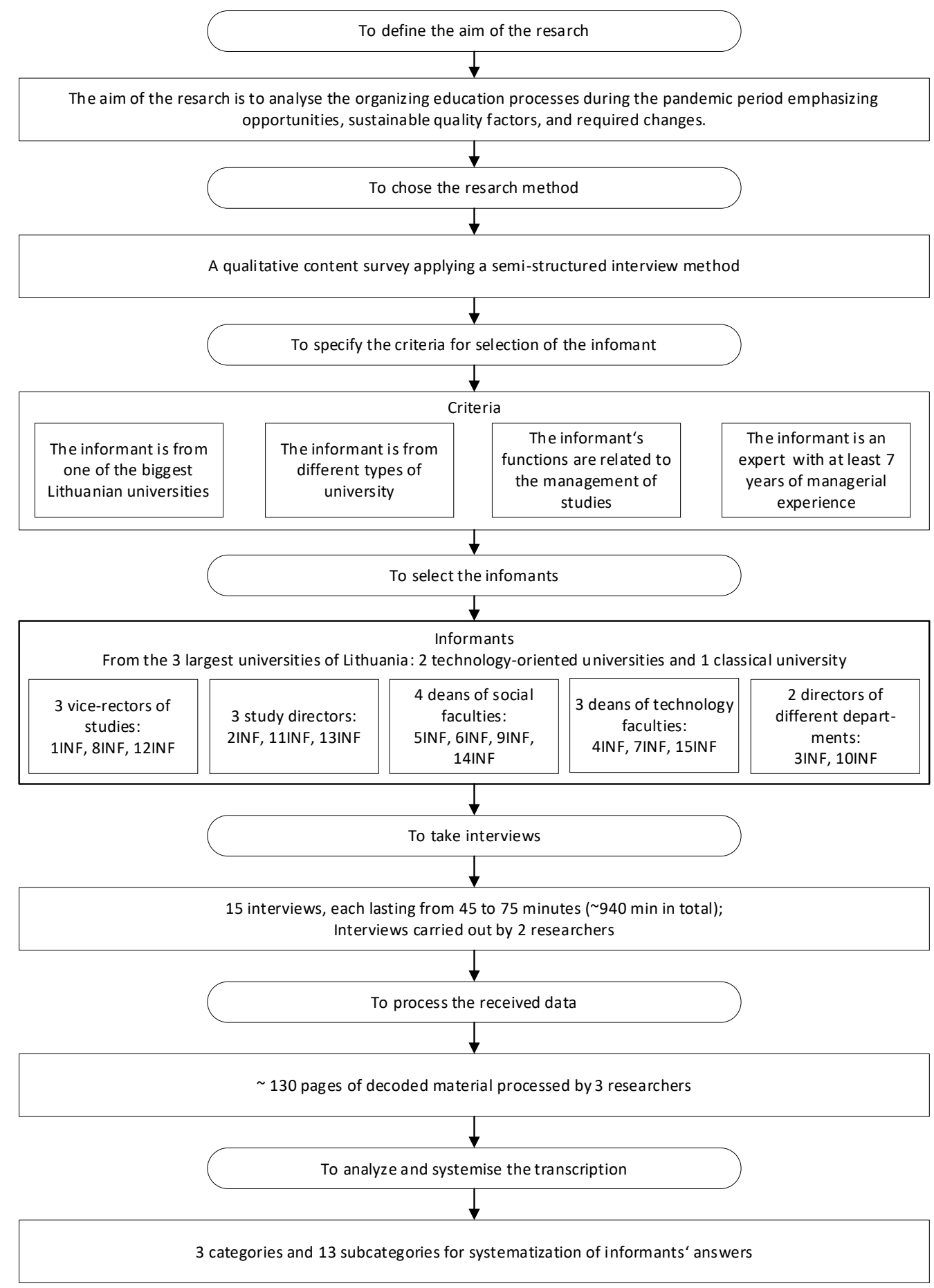

Figure 1. A conceptual framework of the research.

The encoding of informants (codes are seen describing the research results) is as follows: three vice-rectors of studies of different universities (1INF, 8INF, 12INF), three study directors of different universities (2INF, 11INF, 13INF), four deans of social faculties (5INF, 6INF, 9INF, 14INF) and three deans of technology faculties (4INF, 7INF, 15INF), two directors of different departments (3INF, 10INF). The study involved 15 informants-11 men 
and 4 women. All the experts were master's degree holders, and the majority had a doctor's degree.

The interviews with experts were conducted using the Zoom video conferencing platform. Interviews lasted from $45 \mathrm{~min}$ to $75 \mathrm{~min}$. The total duration of all the interviews was about $940 \mathrm{~min}$. The researcher conducting the qualitative research needed to be attentive to address validity and reliability problems. To ensure validity, the researchers applied the principle of triangulation. The received data were decoded and about 130 pages of decoded material were received. To ensure validity, the interviews were carried out by two researchers: an educational scientist and informatics scientist, then the received data were processed by three researchers: an educational scientist and two informatics scientists. The triangulation of the researchers allowed factual or interpretative errors to be corrected. The interdisciplinary approach to the results ensured both validity and perspectives from different scientific fields. Furthermore, the triangulation of data sources was applied, which refers to the consistency, logic, and coherence of the presentation of the information by comparing and checking different sources. In order to ensure validity and reliability, four main criteria were applied: credibility, transferability, dependability, and confirmability. The principle of integrity was also applied in the analysis of the data: the researchers described the links and explained the steps taken. Interview transcription analysis was conducted by using the software for qualitative and mixed methods data analysis MAXQDA. The research methods included: analysis of scholarly literature and qualitative content analysis (qualitative information obtained from the respondents' answers to open-ended questions were analyzed and systemized distinguishing categories, subcategories and presenting respective quotes). Analyzing the data, the answers of the experts were grouped according to the meaning, and respective categories were created. The analysis of research results allowed distinguishing three categories: required changes, opportunities, and quality factors (Figure 2).

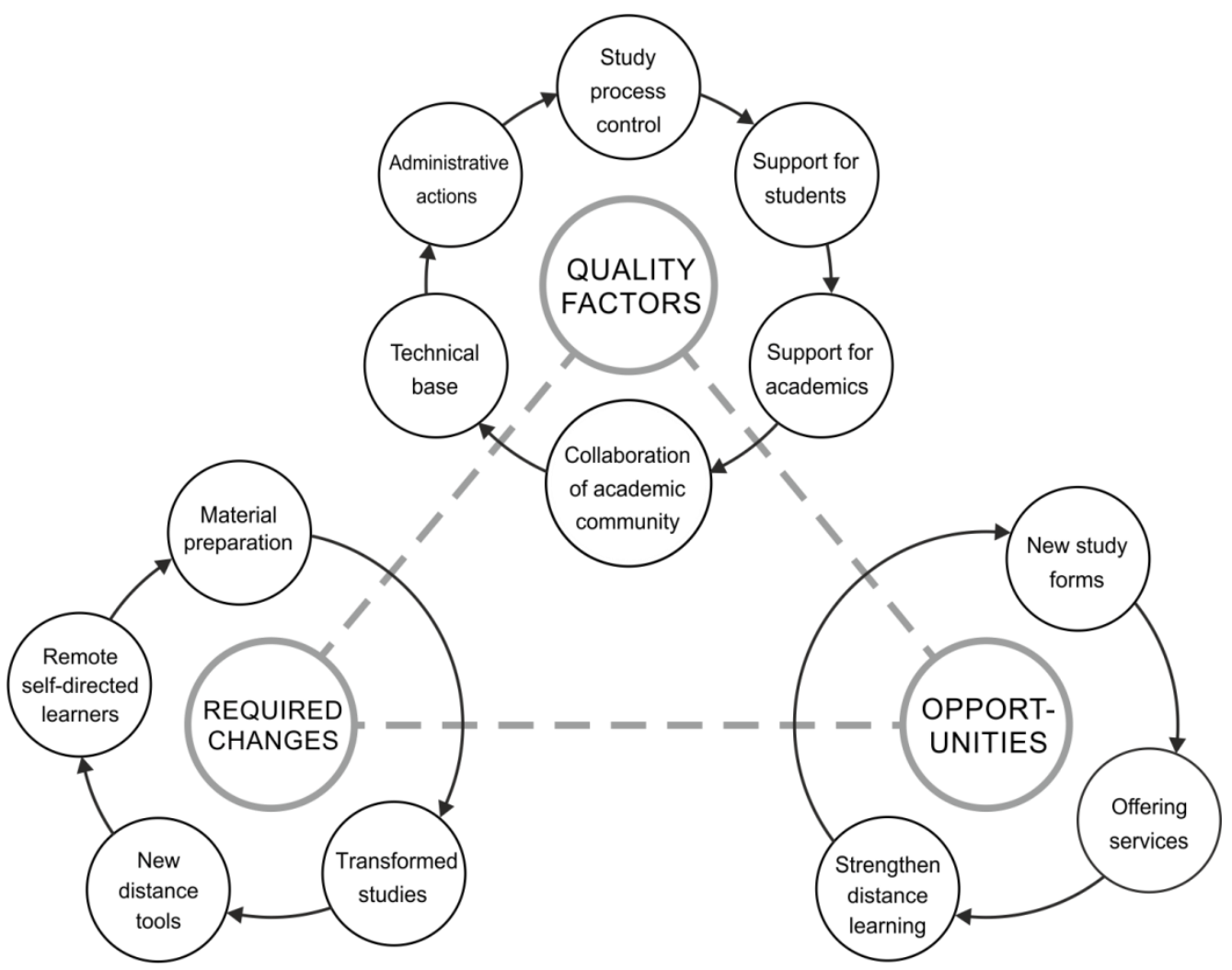

Figure 2. The methodology of the research related to the three main indicators. 
The research questions were developed by the authors of the article to analyze the views of the top university administration. Research ethics were followed in conducting the study and processing the data.

\section{Research Results}

Our research is focused on three main key factors identified in education and raised in the pandemic period, i.e., (1) required key changes for organizations and learning processes, (2) opportunities existing in each organization to ensure a successful study process and (3) quality factors are identified for the successful implementation of distance learning during the pandemic period.

\subsection{Required Key Changes for Organizations and Learning Processes}

Qualitative research results show the main required changes for transformation into distance learning (Figure 3).

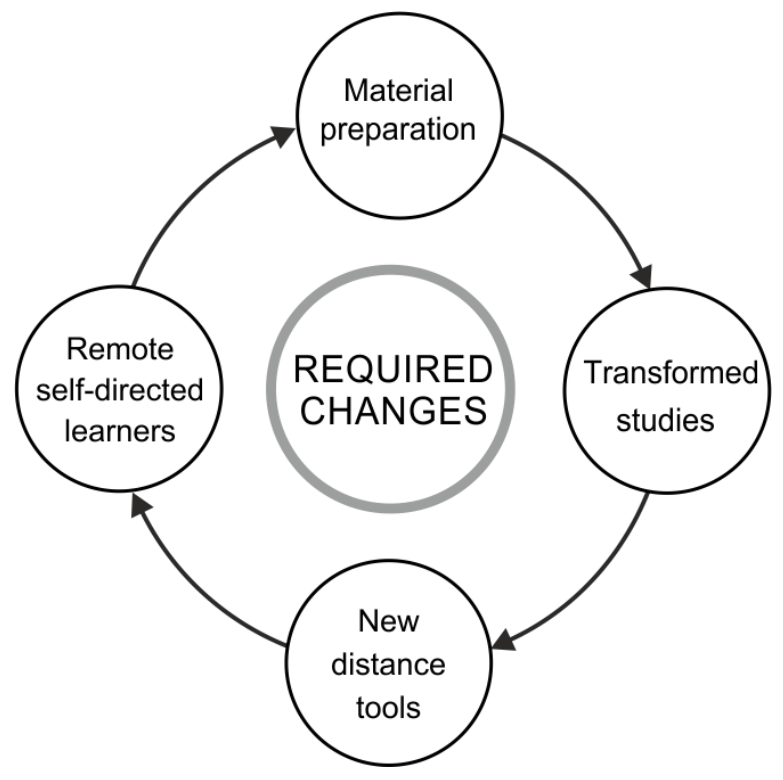

Figure 3. Changes required for transformation into distance learning.

Although there were a lot of discussions regarding the process of managing the situation by transitioning to distance education in the event of a pandemic, thus ensuring the continuity of the quality learning process, such types of learning during the quarantine led to changes. Many elements of traditional studies have also changed as a result of the emergency situation and the transition from face-to-face to distance learning. First of all, the change was related to formal study processes, which also includes in-depth learning processes.

\subsubsection{Transformed Studies}

The informants emphasized the use of the traditional schedule during the period of distance. The informants stated that they put in great efforts to maintain the traditional study schedule, which provided opportunities and necessary conditions to ensure quality studies: 5INF: 'There were instructions stating that is important to conduct lectures on schedule', 13INF: 'Both the lecturers and the administration were encouraged to review the learning process and keep the schedule as it was before when conducting the sessions synchronously. Only in the event of not being to do so, adjustments could be made'. Although the main decisions were made by the central management of universities, the opinions of the lecturers were also considered. Based on the response of the informant, some lecturers also wanted to follow the schedule. 11INF: 'It depends very much on the 
particular department and even on individual lecturers. Some really wanted those lectures to take place synchronously and on schedule. Finally, in many cases, the process went like this'. There have been cases where some institutions let lecturers decide for themselves how and when the study process will take place, but this was hard to control and in order to maintain a schedule approved at the beginning of the semester with clear accounting for contact lectures; therefore, it was decided to return to the traditional schedule. 9INF: 'The situation was evaluated and soon we returned to the activities based on the schedule'.

\subsubsection{Remote Self-Directed Learners}

There were other changes in other studies as well. One of them is the improvement of student attendance. Several informants spoke of this positive change, although some of them said that it was true only for a while and others claimed that it was a permanent change. It is entirely possible that this was due to the specifics of the subject and the lecturer's ability to involve students in the active study process. However, almost everyone emphasized good attendance. 14INF: 'Increased attendance is considered to be a success. Attendance increased up to $100 \%$, which was not the case during regular lectures. Thinking in the long run that distance learning would lead to better attendance, the answer is no because it was just an effect of innovation'.

With regard to profound change, emphasis should also be placed on developing students' self-directed learning. Several informants noticed that the unexpected and even forced transition to distance learning encouraged students to learn more independently and develop learning-to-learn competencies.

Another factor for change in improving students' attendance and developing their independence was the mastery of new distance learning tools. 13INF: 'A large part of lecturers has tried distance learning. It should not be feared, it may not be the main learning method at the university but we could apply it at least in part'. 15INF: 'In these two weeks, we have learned more than ever before. Especially when it comes to getting acquainted with a wide range of tools for distance communication and information sharing, using Zoom and MS Teams'. The research shows that for many lecturers, working remotely was a completely new activity because of a widespread belief that the quality of the study or subject was suffering from it. The pandemic forced everyone to take up teaching activities in a distant way and opened up new opportunities, leading to innovative studies. Informants say this is one of the things that helped to speed up a lot of other processes.

The study found that the development of high-quality distance learning materials has made a significant contribution to the successful transition from contact learning to distance learning. 15INF: 'Records, additional tests, additional materials, various external sources improved the study quality'. The Moodle environment used by Lithuanian universities has been greatly supplemented by subject material prepared by lecturers and adapted for distance learning. 4INF: 'At this point, the amount of lecture material in Moodle has been strongly supplemented'.

The organization and execution of the defense of final theses have undergone the greatest change. Initially, this posed the most challenges and excitement for both university management, faculty, and students. However, the final defense was initially a great concern for many, but preparations were made and led to success. 11INF: 'Students did well and presented, defended their final theses online', 5INF: 'We are glad because we were very prepared for the defence of the final theses, we had met many times, we had meetings with supervisors, with our managers, even with the whole administration'.

It should be emphasized that the biggest change, the transition to working remotely and the other factors of change listed above were a consequence inspired by the collaboration of the academic community. Informants acknowledge that this is also one of the drivers of change, as everyone felt focused and saw the close focus of the academic community in trying to manage the situation. 14INF: 'We learned that our lecturers are actually advanced. They started sharing additional tools and instruments and used them creatively. There were certainly those who then voluntarily sent their own materials to other faculties'. 2INF: 'The 
situation showed that the academic community is focused and that even in uncertain and extreme conditions, the university is able to function, to be able to ensure the study process'.

Although the study process during the quarantine period posed many challenges, these changes opened up new opportunities and even led to several new study processes. One of the most important factors is the internal motivation of lecturers. Various opportunities open up when confidence or readiness to teach at a distance is gained. This is primarily since distance learning was tried and used by all lecturers working during the semester, and not individually as before the quarantine. Thus, massive internal motivation had been gained, and lecturers gained confidence in their own strengths and opened up distance learning opportunities for their subjects, trying new ways of teaching and communicating with students and mastering tools. 2INF: 'We will be using a lot more and bolder elements that we have tested and that work well. Lecturers will no doubt feel much more confident in those processes after testing both the study methods in a variety of ways and the assessment methods they saw paying off. Finally, they will definitely feel much more confident in organizing the process itself.' Thus, it can be stated that compulsory distance learning will reduce the gap between contact and distance learning, as it has encouraged the use of certain distance learning tools and even changes in certain levels or forms of study.

\subsection{Opportunities Existing in Each Organization to Ensure a Successful Study Process}

The rush to move the study process to distance learning due to the pandemic has caused a lot of confusion and uncertainty, but once the situation has been brought under control, it has also opened up a much wider range of study opportunities (Figure 4). The informants identified three main opportunities for transferring organizations into a successful learning process during the pandemic: (1) updating study forms according to the pandemic situation; (2) strengthening distance learning possibilities; and (3) offering new services required by teachers for extra situation (Figure 4).

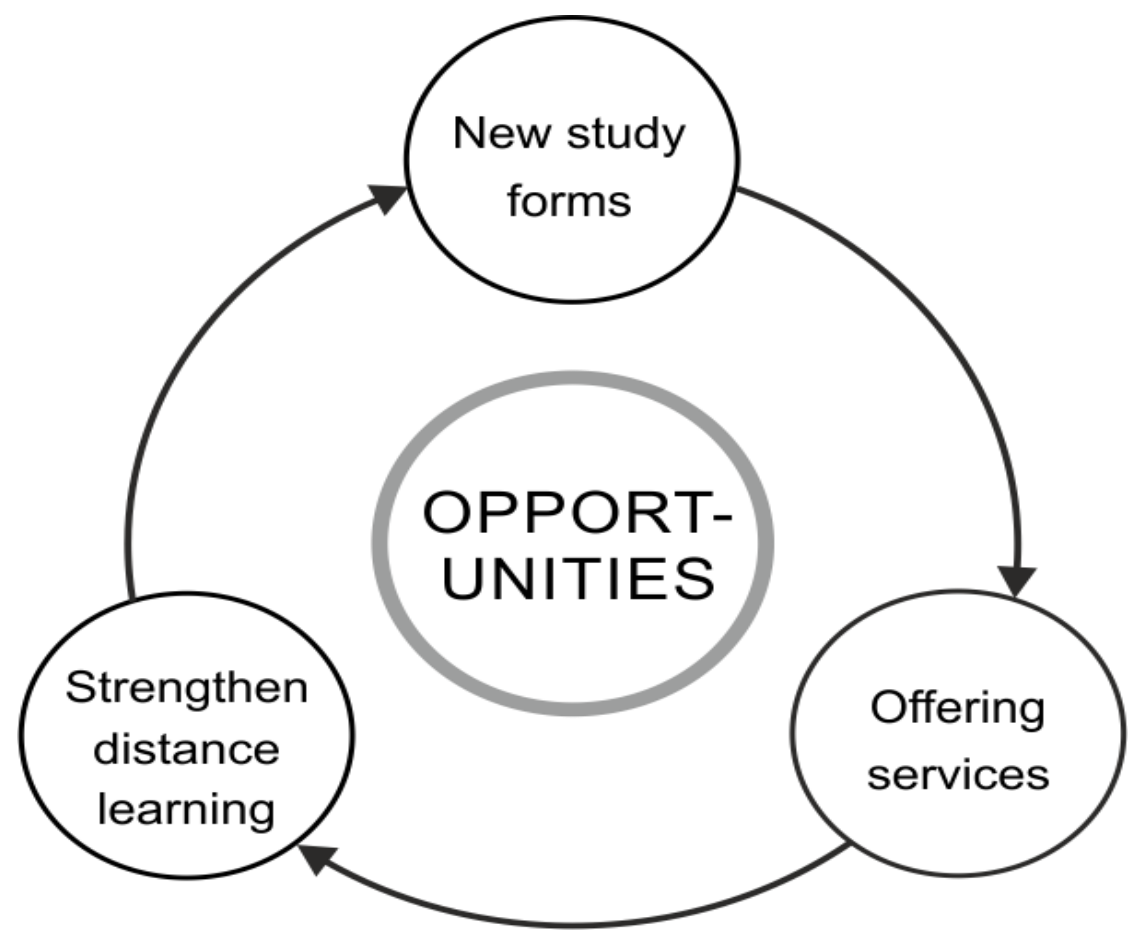

Figure 4. Opportunities opened up by distance learning.

\subsubsection{New Study Forms}

First, the subcategory discussed is the possibility of changing the form of the thesis defense. The change in the transfer of dissertation defense to the remote environment has shown the possibility of communicating with social partners not only directly, which is 
difficult due to their work and schedule, but also virtually/online. This inspired the idea of applying this innovation not only in the above case but also in discussing the quality of study programs, inviting to share experiences with students. 14INF: 'There were various situations and it has allowed us to see that the social partners are now almost $100 \%$ involved in all processes throughout the period, proving that it was a real success'.

Second, representatives of all universities stated that students will have the opportunity to study in a different form of master's degree in the form of blended learning. 1INF: 'That is why we have made a decision regarding master's studies from the first day of September next year (2021). 50\% of the activities in the program can take place remotely. Two days of learning remotely, two days of regular contact. It is up to the lecturers or the head of the study program committee to decide which disciplines should take place remotely'. It should be noted that one university has opened up even wider possibilities by offering distance master's studies in the regions. 5INF: 'Here we are talking about a regional master's degree, where it has already been planned to take place in a distance way. It was planned to take place in the regions directly, then rescheduled to remote'. This form of blended learning provides a greater opportunity for postgraduate study and ensures better attendance at classes. It could be argued that postgraduate studies do not have a lot of laboratory work, but are research-oriented, so the necessary experiments for the final work can be performed on a more flexible schedule.

Third, other forms of study and access to them are open to foreign students (changes in the learning of foreign students). For many lecturers, especially in the fields of technology and engineering, it is an innovation to use a hybrid form of learning. Prior to the pandemic and the quarantine, hybrid learning was mostly applied when a higher education institution has faculties in different cities. Quarantine has shown the possibility that, with the necessary equipment, it is possible to organize such studies even for students abroad. Foreign students choose this option because they cannot come to Lithuania due to the quarantine.

\subsubsection{Strengthen Distance Learning}

First, most informants emphasized that lecturers who have tried and already have a distance learning experience will be more likely to apply elements of distance learning in traditional studies. 5INF: 'Having mastered the distance learning tools, we will definitely occasionally move them to face-to-face studies'; 6INF: 'It is now clear that activities in a virtual learning environment will become more frequent'; 13INF: 'Lecturers plan to move at least part of their subjects to a distance form.' In order to ensure the quality, the lecturers will start preparing for the next semester in advance. As for the relationship between direct and distance learning, there are different options.' 15INF: 'When transitioning to the blended learning, that ratio can be more or less different depending on the modules and students, depending on the particular faculty'; 14INF: 'Theoretical lectures can be conducted at a distance, and we will ask for contact activities in laboratories and exercises because there are things that cannot be changed due to the use of technology'. It should be emphasized that the lecturers saw an opportunity not only to organize the studies more by applying the elements of distance learning but also to use them for organizational work.

During the pandemic, the global shift to distance learning also affected the work of university leadership. Firstly, the opportunity was taken to remotely organize work and hold university management meetings remotely therefore saving time. 8INF: 'One of the good experiences of this is that we clearly understood that organizing administrative meetings remotely has many advantages. The ministry has finally realized how much time it saves on its meetings [...] After the end of the quarantine, this practice has remained and now almost half of the meetings, if not more, is organized remotely. The quality of solutions has not really diminished'.

The use of virtual environments has revealed the possibility of improving the quality of learning content. 6INF: 'The study content will improve since learning material will be uploaded to the virtual learning environment every year and you will be able to update and improve your course every year'. This has also been noticed by university management 
that is considering how to motivate lecturers to do so. 9INF: 'It is possible to motivate by offering additional vacation days, financial motivation, it can be encouraged in other ways, but distance courses need to be prepared.'

\subsubsection{Offering Services}

Distance learning during quarantine has opened up two types of training. This is primarily the preparation of new didactic training for lecturers. After the quarantine, higher education institutions were forced to train their lecturers to work in a virtual learning space. This opened up the possibility of using the videoconferencing platform for the internal needs of the higher education institution. 13INF: 'In order to understand how to ensure learning outcomes, how to ensure academic integrity-we could develop online multi-day in-depth training focused on exactly how to organize that course from an educational perspective.'

The other two opportunities are related to internationalization. The possibility of offering distance learning courses/training at the international level was recognized. Such trust is closely related to the empowered intrinsic motivation of lecturers to do so. During the quarantine, many lecturers took the opportunity to take advantage of the open resources of foreign universities online. This allowed for comparison and inspired a certain notion of untapped opportunities. Therefore, the internal concept and desire of the lecturer promote the external study processes of the higher school. 9INF: 'It turned out that if you want to do something on behalf of the university, such as courses, the university itself has to register it, it has recognized as such to prevent self-proclaimed ones and so on. If we look at the experience of the world's universities, we will see that both the University of Cambridge, the same Princeton, Massachusetts and others have the largest distance learning courses.'

\subsubsection{Limitations of Distance Learning}

Although distance learning has revealed many opportunities in various respects, it also has some limitations. First of all, the limitations of the use of distance learning in certain programs can be seen. 12INF: 'Some study programs cannot be transferred entirely to distance learning, especially in technological science and engineering study programs.' The limitation is not only due to the equipment needed for the above-mentioned studies but also due to the decrease in social skills. 15INF: 'It is not possible to provide absolutely everything remotely, even in the subjects of the Faculty of Informatics, because we are losing social skills, for example, to receive information not only verbally but also to be able to read body language and see more things. It is difficult to assess what you actually see on the other side of the screen. We have limitations, our information field shrinks and we lose certain social skills, such as assessing the situation when a decision needs to be made'. Another subcategory, the irreplaceability of contact work reinforces the limitations of distance learning discussed here. 14INF: 'Nothing will ever change live communication'; 4INF: 'After all, over the centuries, direct contact between the student and the lecturer has not disappeared anywhere in universities. Finally, students also learn from the faculty. There are really smart people that make an impact on students. You won't pass it on through the computer screen.'

\subsection{Quality Factors Are Identified for the Successful Implementation of Distance Learning during the Pandemic Period}

The main quality factors identified by informants are: (1) technical base; (2) administration actions focused on the study processes quality; (3) study process control; (4) support for students; (5) support for academics, including methodological and technological support; and (6) collaboration and sharing good practices inside the academic community (Figure 5). 


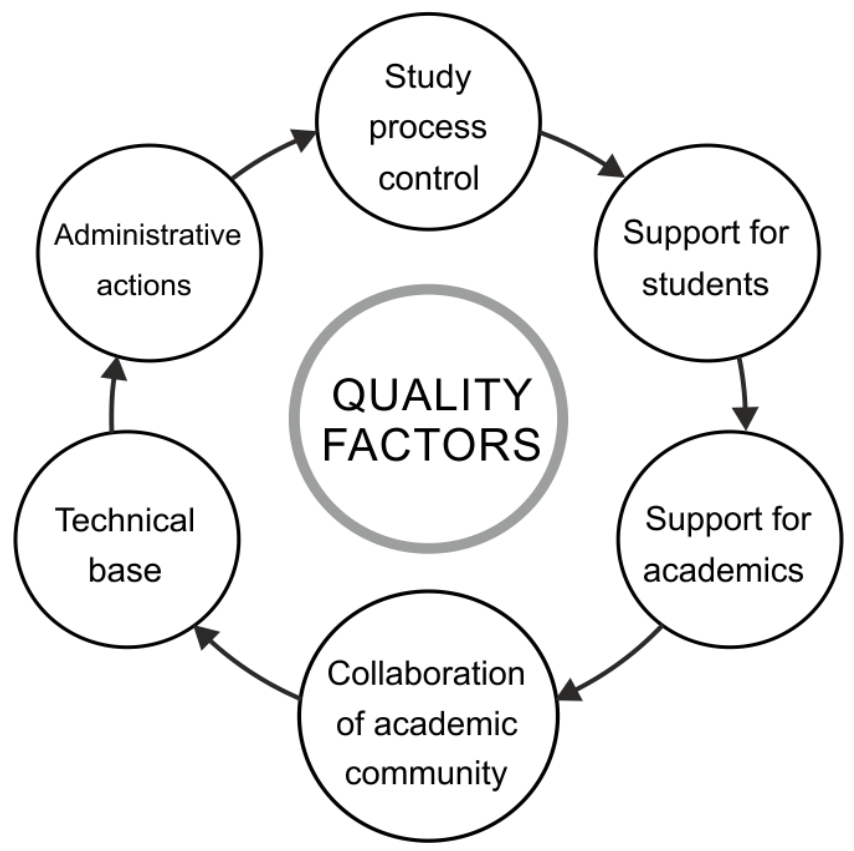

Figure 5. Sustainable quality factors in distance learning.

\subsubsection{Administrative Actions}

Research has shown that in order to ensure the quality of studies and change from one form of study to another (from face-to-face learning to distance learning during the pandemic period), centralized decisions at the institutional level and a sufficient preparatory period are required. Most of the informants (nine informants) emphasized the importance of the two-week preparatory period for the quality of studies by changing the form of both studies and work. During the decision-making process, the specifics of studies and the organization of laboratory work had to be considered 15INF: 'It was coordinated centrally and a lot of things had to be reconsidered. We had to consider what method to choose, what tool to apply for examination of laboratory works and how to organize and implement it'. Those universities that chose not to take a break from the preparation period consequently had studies of lower quality. 14INF: 'We did everything really poorly'.

The timely decisions of the management, administering the studies, and the centralized management at the Senate level were also important for the study quality 8INF: 'The Senate said that we would meet if it is necessary to make timely decisions. And those meetings actually took place.' A similar practice was present in the Rectorate, where meetings were held weekly. 2INF: 'It was where most of the attention was paid specifically for studies.' Meanwhile, the institutional-wide planning of the activities was done by the Department of Studies. Therefore, the centralized work of university management and the decisions made affected the study quality. It should be noticed that management decisions were governed by internal legislation. These documents were relevant to both lecturers and students in the direct study process. 1INF: 'About 10 documents were prepared and approved by the order of the Rector. There has also been a lot of pieces of legislation, mostly temporary, that have dealt specifically with changes in the study process.' The main challenges were the final theses, so a lot of attention was given during the preparation of these documents. 11INF: 'We needed to reassess some of the procedures and adapt them to the process of distance studies.'

In order to ensure study quality, it is necessary to react flexibly in extreme conditions. It requires searching and the adoption of flexible solutions for practical work in order to achieve the intended learning outcomes. The organization of laboratory or practical work posed many challenges, so appropriate decisions had to be made. 14INF: 'Some moved 
such activities to the next semester, others found the required software [...]'. 7INF: 'They were replaced by written tasks or in a form that can be carried out remotely'.

The initiatives of the Study Program Committee are important during the preparation for the transition to distance studies, as there is a need to assess the available study resources and anticipate what resources are lacking, encourage lecturers to develop them and provide support. 5INF: 'We worked together with the lecturers for those two weeks to ensure the maximum amount of material. There was no module left that didn't have the information on Moodle'.

\subsubsection{Collaboration of Academic Community}

Another quality factor during the pandemic period of COVID-19 is the ability to cooperate in decision making and the communication between management and the community. This was emphasized by all informants and they all listed different addresses, means of communication or goals.

First of all, the communication between the different levels of leadership: central administration, faculty deans, vice-deans, and heads of departments: 'Of course, teamwork was important [...] Discussing a variety of things, sharing good practices, what works well, what could be done differently' (2INF).

Secondly, communication between top management and the faculty is crucial in explaining to them 'why particular decisions have been made' (1INF). 3INF: 'There have been a lot of efforts to keep the communication with the lecturers on all issues. They are the people that influence the study process and its quality the most. There has been a great deal of effort to inform them about all sorts of different decisions. While communicating with students, it is important to explain not only the decisions that have already been made but also to communicate clearly, explain things that are not clear as well as tell them when to expect further information. They were told how 'distance lectures work and how they should behave during them', as well as 'principles of academic integrity' (13INF). In addition, various recommendations are being drawn up for distance learning.

Quality studies and their success during the quarantine were determined by the fact that the central or faculty management responded to opinions of lecturers conducting distance studies, rapidly addressed the problems, and carried out prevention. 1INF: 'After each lecture, lecturers used to write to us, the Directorate of Studies, the vice-rector or the dean, or the Academic Support Centre about the difficulties, what kind of training they wanted or what problems were, or even shared good practices if the lecture succeeded'. This provision of teaching experience to the central management ensured the preparation of temporary documents regulating the study process, which covered a wide range of study programs offered by different faculties.

\subsubsection{Support for Academics}

One form of cooperation is when management provides support to the academic community. The results of the study show that more than half of the informants emphasized the creation of an additional online block/page/section on the website that publishes all necessary, constantly updated information. 11INF: 'Methodological and technical information for lecturers, advice for students, the information provided to scientists, administrators and all members of the community. Topical issues are systematically presented, updated so that people can have a single point of accesses.' In addition, some universities offered another form where lecturers could receive consultation directly by phone. 3INF: 'We try to respond to those calls as much as we can. When you see a problem, you try to address it as quickly as possible to ensure that the problem does not persist'.

Timely and continuing academic support for lecturers is very important. Analysis of the study data reveals two quality factors related to support for lecturers. The first one is when support for lecturers was offered using centralized decision making, and the second one was when the initiative was taken by the staff of the E-learning Technologies Centre. 
Most informants stressed the importance of providing lecturers with initial and then continuous support during the preparation period by teaching them how to master distance learning tools. 13INF: 'The E-learning Technology Centre has conducted training weekly, sometimes even twice a week, on how to use tools, also prepared instructions for using Zoom, Teams'; 7INF: 'There have been specific training on how to prepare tests, how to make some recommendations regarding final theses etc.'.

In addition to training, information was given to lecturers via e-mail about various recommendations to be used when preparing or conducting distance lectures, and these recommendations were broad in scope. 1INF: 'Methodological material was being developed for lecturers on how to make a didactic use of platforms, how to provide feedback to students, how to organize group work, examination, use the open-book method, etc.'; 4INF: 'Afterwards those instructions and short videos were very helpful'.

Another decision on assisting lecturers to ensure the quality of studies was taken. It was decided to organize the exchange of best practices. This was carried out either on a university-wide basis or within the faculty. Several informants emphasized their importance and positive impact on the studies. 8INF: 'The Department of Quality and Study Development, which has mobilized some foreign lecturers, has been truly active. They organized such workshops, shared experiences or carried out remote training', 14INF: 'We did internally, at the initiative of our own lecturers who are advanced in the use of technology'. It should be noted that if training to work remotely usually took place at the beginning of quarantine on general issues, then the exchange of best practices was usually organized later as if to deepen the competences of lecturers. A common issue for all lecturers was how to organize student examinations. 15INF: 'Many people were very active in sharing ideas with each other on how to organize examination and testing, whether to take tests or use other types of written tasks'. One of the greatest needs for lecturers was ensuring academic integrity. Only on a systematic and broad-scale can this be achieved, not on an individual basis.

\subsubsection{Support for Students}

Development of additional support measures for students. The quality factors of the study process are directed to support students. A number of measures had been taken and it should be noted that the provision of technical equipment was only one form of support, while others concerned academic and financial support. Some informants said they were applying to a one-stop-shop during the quarantine period so that students would get all the information they needed in a single place. First of all, when it came to academic support, unified questions were 'prepared together with answers on the website so that as many people as possible could access them'. 2INF: 'A common email was created for students who could contact at the beginning of the quarantine and each individual problem was directly addressed, for example, quarantine in dormitory'. Secondly, as financial support, students could receive a social scholarship if needed. 11INF: 'Opportunity to receive social scholarships was communicated to everyone'. Close cooperation with members of Students' Representation or a large number of students in general, facilitates the notice and elimination of issues.

As a separate form of support for students, psychologist's help should be distinguished. This was emphasized by the management of several universities. 2INF: 'A psychologist at our university provided psychological counselling remotely since there was an increasing need for it'. 13INF: 'We have two psychologists, and we asked them to prepare recommendations. These recommendations were prepared for both students and lecturers.'

\subsubsection{Technical Base}

Technical provision for community members. Improving/developing a technical base is one of the most important quality factors. First of all, it was decided to purchase Zoom licenses for videoconferencing enabling lectures longer than $40 \mathrm{~min}$. 12INF: 'We understood 
the need and had to buy additional licenses abruptly to make better use of the lecture'. Secondly, other necessary technical means were provided and the need was learned from the faculties. 6INF: 'Since we have tablets, we have distributed them. We even distributed and allowed taking stationary computers to those who needed them and could take them'. Third, some universities made decisions regarding additional rooms to record lectures for the purposes of the faculty: 'We bought and prepared two recording studies: one on the $X$ Street, where we have a building and the other one right here, so it is easier for lecturers to record lectures' (6INF).

\subsubsection{Study Process Control}

Quality control is one of the processes that ensure the quality of studies. However, only a few of the informants mentioned the control of the process. However, analyzing the obtained research results in various sections, it can be observed that the control of the study process in extreme study conditions pays off. This way, students are not left to work on their own but rather the traditional form of learning is maintained while learning remotely. 5INF: 'Therefore, the faculty had decided to check the schedules for the first two weeks. These may have been drastic measures but once we started and found that lecturers understood the instructions, we proceeded to stop the checks. We wanted to make sure that it was going according to schedule and that the lecturer was actually meeting with students since the contact was very important'.

\section{Conclusions and Discussion}

After analyzing the data of the qualitative research on the organization of the educational process during the pandemic period in dealing with administrative issues, a close connection between opportunities, challenges, and sustainable quality factors was found. These categories have a horizontal link where changes have an impact and open up new opportunities, requiring sustainable quality factors. The COVID-19 pandemic forced higher education institutions to rapidly adapt to new conditions and ensure the transition of the study process into distance education. New challenges associated with online teaching and learning will create a space for innovative thinking and innovative solutions [33]. This type of transformation led to changes in the study process and has opened new opportunities gradually moving from a stressful and unstable situation.

Therefore, the category of change has revealed formal and informal changes in studies. As all efforts were concentrated on a smooth transition from contact to distance learning and the provision of quality studies, the informal part of the studies was affected more: various events were cancelled or they took on a different form. Formal studies tried to maintain the same schedule to make it easier to control contact and student self-study hours. Adaptation, organization, and implementation of specialized subjects experienced the most changes. There were issues since some of the laboratory works or practical assignments could not be adapted and carried out remotely in order to achieve the expected study results. Furthermore, the organization and execution of the final thesis defense were challenging but these processes were managed successfully and therefore most of the issues were solved as well. Changes caused most problems to those subjects or units of study programs that required practical skills and to the experiments necessary for final projects. However, changes have also brought some positivity as well. The research revealed deep changes in the way students learn, driven by the quality of teaching activities. By making necessary changes to studies and adapting them to distance learning, lecturers did it responsibly. They started preparing for lectures anew, mastering new distance learning tools, introduced innovative study elements and developed high-quality distance learning material. This led to an improvement in student attendance and developed their learning skills. It is important to notice that they were successful.

By reorganizing the study process and adapting it to distance learning, lecturers did so responsibly by re-preparing for lectures, using new innovative learning tools, introducing many innovative study elements, and preparing high-quality distance learning materials. 
This led to an improvement in student attendance and the development of their independent learning skills. Belonging to community and the link is of utmost importance in distance learning as well as development of meaningful relationships with one's instructors and classmates, not excluding goals and interests similar to groupmates [52]. It is important to notice that the successful change was due to a focused and collaborative academic community across the university and not just at the faculty level. A flexible and supporting online learning environment was able to fight against social isolation and increase social participation, but lecturers needed constant help to learn how to enable them to do this practically $[18,36]$.

Considering new opportunities, it should be mentioned that they were motivated by the increased internal motivation of lecturers. They gained self-confidence and prepared (learned) to teach remotely. Therefore, deep reasons (internal motivation of lecturers) have primarily influenced the implementation and development of distance studies not only during the pandemic period but also after it. Lecturers will want to apply the elements of distance learning in traditional studies, including when writing or defending their final project, they have also opened up opportunities and have shown that the work they put in during the pandemic is valuable and sustainable, as the quality of subject content can be improved annually. Lecturers will need to engage in novel methods to achieve effective teaching outcomes, which may affect the quality of tertiary education [8].

In addition, the pandemic period has influenced and opened up new opportunities for the work of university management, where remote work elements are already or will be applied in the future. Their use has led to closer communication between the central university leadership and the faculty administration. Secondly, it should be noted that new forms of study have been opened, not only nationally but also internationally. All universities involved in the research confirmed the realization of a mixed form (blended learning) master's degree, as well as expanded opportunities for foreign student studies and their mobility and that of lecturers. For this reason, hybrid studies will be applied in many cases. Most authors [52-54] suppose that online, partially online, or mixed learning processes are most frequently related to the inverted class method. However, regardless of the selected online learning method, the most important points of the online learning process for students are through the promotion of self-learning, interaction with teaching staff, planning activities, including the preparation of an appropriate environment, the use of multimedia, and a proper and accepted evaluation system. Thirdly, the pandemic has opened up opportunities to provide services internally and to other institutions at the national and international level, including the provision of didactic training for teachers or other distance courses/training.

Sustainable quality assurance factors are essential for the success of opportunity processes that are change driven. The research revealed that sustainable quality factors are divided into six, closely related types: administrative actions, cooperation between different levels of management and the academic community, development and maintenance of a technical base, timely and continuous support for lectures, comprehensive support for students, and study process control.

The limitations of this research arise from engaging representatives from different universities due to the difference in experience levels and the small number of informants. The opportunities, quality factors, and required changes were formulated and based on the attitudes of expert representatives of the university authorities who participated in the research. Lecturers and students, whose opinions and experience could supplement the acquired research results, did not participate in the research. Only considering the experience of the latter, the experts formulated their attitude.

It can also be foregrounded that, rather than directly, which is more common in conducting in-depth interviews, the research data were collected using an online tool, for example Zoom. The subjectivity factor should also be considered, as this might have affected the research data during the analysis of the qualitative data. 
The conducted study reflects the situation of higher education institutions in Lithuania during the emergency period but can be transferred to other countries as well. Further research based on a similar framework could compare the experiences of different countries or geopolitical regions. Such research would be one of the priorities for the future. Further research could include comparative qualitative changes and encountered country or institution-specific problems and challenges as well as suggesting solutions.

Author Contributions: Conceptualization, V.N. and V.D.; Methodology, V.N. and R.B.; Formal analysis, R.B., E.J. and D.G.; Writing—Original Draft Preparation, V.N., V.D. and D.G.; Writing—Review \& Editing, R.B., E.J. and D.G.; Visualization, V.D. and E.J.; Project administration, D.G.; Funding Acquisition, D.G. All authors have read and agreed to the published version of the manuscript.

Funding: The research is supported by Lithuanian Research Council financed project "Model of distance working and learning organization and recommendations for extreme and transition period" (EKSTRE) (1 June 2020-31 December 2020). Grant Agreement S-COV-20-20.

Institutional Review Board Statement: Ethical review and approval were waived for this study, as this study involves no more than minimal risk to subjects.

Informed Consent Statement: Informed consent was obtained from all subjects involved in the study.

Data Availability Statement: The data presented in this study are available on request from the corresponding author. The data are not publicly available due to data restriction policy by the grant provider.

Conflicts of Interest: The authors declare no conflict of interest.

\section{References}

1. Burgess, S.; Sievertsen, H.H. Schools, Skills, And Learning: The Impact of COVID-19 on Education. 2020. Available online: https://voxeu.org/article/impact-covid-19-education (accessed on 30 December 2020).

2. Chen, Y.; Hou, A.Y.C.; Huang, L. Development of distance education in Chinese higher education in perspectives of accessibility, quality and equity under COVID-19. Asian Educ. Dev. Stud. 2021. ahead-of-print. [CrossRef]

3. Quadir, B.; Zhou, M.H. Students perceptions, system characteristics and online learning during the COVID-19 epidemic school disruption. Int. J. Distance Educ. Technol. 2021, 19, 1-19. [CrossRef]

4. Chen, C.M.; Li, M.C.; Chang, W.C.; Chen, X.X. Developing a topic analysis instant feedback system to facilitate asynchronous online discussion effectiveness. Comput. Educ. 2020, 163, 104095. [CrossRef]

5. El Firdoussi, S.; Lachgar, M.; Kabaili, H.; Rochdi, A.; Goujdami, D.; El Firdoussi, L. Assessing distance learning in higher education during the COVID-19 pandemic. Educ. Res. Int. 2020, 2020, 8890633. [CrossRef]

6. Hilton, R.; Moos, C.; Barnes, C. A Comparative Analysis of Students' Perceptions of Learning in Online versus Traditional Courses. E-J. Bus. Educ. Scholarsh. Teach. 2020, 14, 2-11. Available online: https://files.eric.ed.gov/fulltext/EJ1292855.pdf (accessed on 30 December 2020).

7. Mseleku, Z. A literature review of e-learning and e-teaching in the era of COVID-19 pandemic. J. Innov. Sci. Res. Technol. 2020, 5, 588-597.

8. Trespalacios, J.; Snelson, C.; Lowenthal, P.; Uribe-Flórez, L.; Perkins, R. Community and connectedness in online higher education: A scoping review of the literature. Distance Educ. 2020, 42, 5-21. [CrossRef]

9. Rajkumar, R.P. COVID-19 and mental health: A review of the existing literature. Asian J. Psychiatry 2020, 52, 102066. [CrossRef]

10. Rossi, R.; Socci, V.; Talevi, D.; Mensi, S.; Niolu, C.; Pacitti, F.; Di Lorenzo, G. COVID-19 pandemic and lockdown measures impact on mental health among the general population in Italy. Front. Psychiatry 2020, 11, 1-6. [CrossRef]

11. Tandon, R. COVID-19 and mental health: Preserving humanity, maintaining sanity, and promoting health. Asian J. Psychiatry 2020, 51, 102256. [CrossRef]

12. Chen, T.; Peng, L.; Yin, Y.; Rong, J.; Yang, J.; Cong, G. Analysis of user satisfaction with online education platforms in China during the COVID-19 pandemic. Healthcare 2020, 8, 200. [CrossRef] [PubMed]

13. Goh, P.S.; Sandars, J. Rethinking scholarship in medical education during the era of the COVID-19 pandemic. Med. Ed. Publ. 2020, 9, 1-14. [CrossRef]

14. Teräs, M.; Suoranta, J.; Teräs, H.; Curcher, M. Post-COVID-19 education and education technology "solutionism": A seller's market. Postdigit. Sci. Educ. 2020, 2, 863-878. [CrossRef]

15. Costa, L.A.; Pereira Sanches, L.M.; Rocha Amorim, R.J.; do Nascimento Salvador, L.; dos Santos Souza, M.V. Monitoring academic performance based on learning analytics and ontology: A systematic review. Inform. Educ. 2020, 19, 361-397. [CrossRef]

16. Sahu, P. Closure of universities due to coronavirus disease 2019 (COVID-19): Impact on education and mental health of students and academic staff. Cureus 2020, 12, e7541. [CrossRef] 
17. Crawford, J.; Butler-Henderson, K.; Rudolph, J.; Malkawi, B.; Glowatz, M.; Burton, R.; Magni, P.; Lam, S. COVID-19: 20 countries' higher education intra-period digital pedagogy responses. J. Appl. Learn. Teach. 2020, 3, 1-20. [CrossRef]

18. Garbe, A.; Ogurlu, U.; Logan, N.; Cook, P. COVID-19 and Remote Learning: Experiences of Parents with Children during the Pandemic. Am. J. Qual. Res. 2020, 4, 45-65. [CrossRef]

19. Kerres, M. Against all odds: Education in Germany coping with COVID-19. Postdigit. Sci. Educ. 2020, 2, 690-694. [CrossRef]

20. Aboagye, E.; Yawson, J.A.; Appiah, K.N. COVID-19 and E-learning: The challenges of students in tertiary institutions. Soc. Educ. Res. 2020, 2, 1-8. [CrossRef]

21. Bao, W. COVID-19 and online teaching in higher education: A case study of Peking University. Hum. Behav. Emerg. Technol. 2020, 2, 113-115. [CrossRef]

22. Dawadi, S.; Giri, R.; Simkhada, P. Impact of COVID-19 on the education sector in Nepal: Challenges and coping strategies. Sage 2020, 1-16, (Preprint). [CrossRef]

23. Prokopenko, I.; Berezhna, S. Higher education institutions in Ukraine during the coronavirus, or COVID-19, outbreak: New challenges vs. new opportunities. Rev. Rom. Pentru Educ. Multidimens. 2020, 12, 130-135. [CrossRef]

24. Iglesias-Pradasa, S.; Hernández-Garcíaa, A.; Chaparro-Peláeza, J.; Prietob, L. Emergency remote teaching and students academic performance in higher education during the COVID-19 pandemic: A case study. Comput. Hum. Behav. 2021, 119, 106713. [CrossRef]

25. Paudel, P. Online education: Benefits, challenges and strategies during and after COVID-19 in higher education. Int. J. Stud. Educ. 2021, 3, 70-85. [CrossRef]

26. Assunção Flores, M.; Gago, M. Teacher education in times of COVID-19 pandemic in Portugal: National, institutional and pedagogical responses. J. Educ. Teach. 2020, 46, 507-516. [CrossRef]

27. Dorobăţ, I. Models for measuring e-learning success in universities: A literature review. Inform. Econ. 2014, 18, 77-90. [CrossRef]

28. Rizun, M.; Strzelecki, A. Students' acceptance of the COVID-19 impact on shifting higher education to distance learning in Poland. Int. J. Environ. Res. Public Health 2020, 17, 6468. [CrossRef]

29. Abidah, A.; Hidaayatullaah, H.N.; Simamora, R.M.; Fehabutar, D.; Mutakinati, L. The impact of COVID-19 to Indonesian education and its relation to the philosophy of "Merdeka Belajar". Stud. Philos. Sci. Educ. 2020, 1, 38-49. [CrossRef]

30. Dubey, P.; Pandey, D. Distance learning in higher education during pandemic: Challenges and opportunities. Int. J. Indian Psychol. 2020, 8, 43-46. [CrossRef]

31. Ismaili, Y. Evaluation of students attitude toward distance learning during the pandemic (COVID-19): A case study of ELTE university. Horiz. 2021, 29, 17-30. [CrossRef]

32. Kabir, M.R.; Islam, M.A.; Deena, S.A. Explaining the adoption of technology-based design of higher education during and after COVID 19 period from a developing country perspective. Int. Des. Archit. 2020, 46, 88-119.

33. Bryson, J.R.; Andres, L. COVID-19 and rapid adoption and improvisation of online teaching: Curating resources for extensive versus intensive online learning experiences. J. Geogr. High. Educ. 2020, 44, 608-623. [CrossRef]

34. Cicha, K.; Rizun, M.; Rutecka, P.; Strzelecki, A. COVID-19 and higher education: First-year students' expectations toward distance learning. Sustainability 2021, 13, 1889. [CrossRef]

35. Gardner, L. COVID-19 has forced higher ed to pivot to online learning. Here are 7 takeaways so far. Chron. High. Educ. 2020, 20, 1-6.

36. Ratten, V. Coronavirus (COVID-19) and the entrepreneurship education community. J. Enterprising Communities People Places Glob. Econ. 2020, 14, 753-764. [CrossRef]

37. Aucejo, E.M.; French, J.; Ugalde Araya, M.P.; Zafar, B. The impact of COVID-19 on student experiences and expectations: Evidence from a survey. J. Public Econ. 2020, 191, 104271. [CrossRef]

38. Demuyakor, J. Coronavirus (COVID-19) and online learning in higher institutions of education: A survey of the perceptions of Ghanaian international students in China. Online J. Commun. Media Technol. 2020, 10, e202018. [CrossRef]

39. Moorhouse, B.L. Adaptations to a face-to-face initial teacher education course 'forced' online due to the COVID-19 pandemic. J. Educ. Teach. Int. Res. Pedagog. 2020, 46, 609-611. [CrossRef]

40. Sandars, J.; Correia, R.; Dankbaar, M.; de Jong, P.; Goh, P.S.; Hege, I.; Pusic, M. Twelve tips for rapidly migrating to online learning during the COVID-19 pandemic. MedEdPublish 2020, 9, 1-19. [CrossRef]

41. Dorn, E.; Hancock, B.; Sarakatsannis, J.; Viruleg, E. COVID-19 and student learning in the United States: The hurt could last a lifetime. McKinsey Co. 2020, 1, 1-9.

42. Gonzalez, T.; De La Rubia, M.A.; Hincz, K.P.; Comas-Lopez, M.; Subirats, L.; Fort, S.; Sacha, G.M. Influence of COVID-19 confinement on students performance in higher education. PLoS ONE 2020, 15, e0239490. [CrossRef]

43. Rupnow, R.L.; LaDue, N.D.; James, N.M.; Bergan-Roller HE, A. Perturbed system: How tenured faculty responded to the COVID-19 shift to remote instruction. J. Chem. Educ. 2020, 97, 2397-2407. [CrossRef]

44. Lima, E.F.C.; Siebra, C.A. Design of learning objects for collaboration promotion and their effects on students behaviour. Inform. Educ. 2021, 20, 85-106. [CrossRef]

45. Saunders, P.; Kim, Y.; Dobbs, D. Innovative gerontology in higher education: Transformative effects of the pandemic. Innov. Aging 2021, 5, 579-580. [CrossRef]

46. Dietrich, N.; Kentheswaran, K.; Ahmadi, A.; Teychené, J.; Bessière, Y.; Alfenore, S.; Laborie, S.; Bastoul, D.; Loubière, K.; Guigui, C.; et al. Attempts, successes, and failures of distance learning in the time of COVID-19. J. Chem. Educ. 2020, 97, 2448-2457. [CrossRef] 
47. Mourtzisa, D.; Panopoulosa, N.; Angelopoulosam, J.; Zygomalasa, S.; Dimitrakopoulosa, G.; Stavropoulosa, P. A hybrid teaching factory model for supporting the educational process in COVID-19 era. Procedia CIRP 2021, 104, 1626-1631. [CrossRef]

48. Beech, N.; Anseel, F. COVID-19 and Its Impact on Management Research and Education: Threats, Opportunities and a Manifesto. Br. J. Manag. 2020, 31, 447-449. [CrossRef]

49. Lee, K.; Fanguy, M.; Lu, X.S.; Bligh, B. Student learning during COVID-19: It was not as bad as we feared. Distance Educ. 2021, 42, 164-172. [CrossRef]

50. Liguori, E.; Winkler, C. From offline to online: Challenges and opportunities for entrepreneurship education following the COVID-19 pandemic. Entrep. Educ. Pedagog. 2020, 3, 346-351. [CrossRef]

51. Žydžiūnaitė, V.; Sabaliauskas, S. Kokybiniai Tyrimai. Principai ir Metodai; Vaga: Vilnus, Lithuania, 2017. (In Lithuanian)

52. Artero Escartin, I.; Domeneque Claver, N. Dar la vuelta a la enseñanza. Una experiencia de Flipped Classroom en Economía Publica. E-publica. Rev. Electrónica Sobre Enseñanza Econ. Pública 2018, 22, 51-75.

53. Bergmann, J.; Sams, A. Flip Your Classroom: Reach Every Student in Every Class Every Day; International Society for Technology in Education: Washington, DC, USA, 2012.

54. González Fernández, M.O.; Huerta Gaytán, P. Experiencia del aula invertida para promover estudiantes prosumidores del nivel superior. RIED. Rev. Iberoam. Educ. Distancia 2019, 22, 245-263. [CrossRef] 